\title{
Value of computed tomography of the abdomen and chest in investigation of Cushing's syndrome
}

\author{
F E WHITE, M C WHITE, P L DRURY, I KELSEY FRY, G M BESSER
}

\begin{abstract}
Computed tomography (CT) scans were performed on 37 patients with biochemically proved Cushing's syndrome to evaluate the role of CT in the investigation of this condition. CT rapidly and correctly identified all 15 adrenocortical tumours, distinguishing five carcinomas from the 10 adenomas. In ACTH-dependent Cushing's syndrome appreciable bilateral adrenal enlargement was common in patients with an ectopic source (6 of 10 cases), while those with a pituitary source usually had normal sized adrenals (9 of 10). Two patients with a history of over seven years had bilateral adrenal nodules. CT was more accurate in locating a primary ectopic source of ACTH (5 of 12 cases) than any other technique and was particularly valuable in detecting small $(<1.5 \mathrm{~cm})$ peripheral lung carcinoid tumours which may be undetectable by conventional $x$-ray techniques.

Its speed, accuracy, and simplicity make CT the technique of choice both to show the adrenal anatomy and to locate a suspected ectopic ACTH-secreting tumour in patients with proved Cushing's syndrome.
\end{abstract}

\section{Introduction}

Most patients with Cushing's syndrome have inappropriately increased secretion of adrenocorticotrophin (ACTH), usually from the pituitary gland but occasionally from an ectopic

St Bartholomew's Hospital, London EC1A 7BE

F E WHITE, MRCP, FRCR, research fellow, department of radiology (now consultant radiologist)

P L DRURY, MRCP, senior registrar, department of medicine

I KELSEY FRY, FRCP, FRCR, director of radiology

G M BESSER, MD, FRCP, professor of endocrinology

Royal Postgraduate Medical School, Hammersmith Hospital, London W13 0HS

M C WHITE, MRCP, MRC fellow tumour. The remainder of cases are due to adrenal tumours secreting cortisol. ${ }^{1}$

Once Cushing's syndrome has been diagnosed, the possible causes are usually distinguished by complex biochemical tests. ${ }^{2}$ Radiological investigations include a chest $x$-ray examination and assessment of the pituitary fossa, but additional procedures such as isotope scanning of the adrenals, ${ }^{3}$ bronchoscopy, whole lung tomography, and selective venous sampling for $\mathrm{ACTH}^{4}$ and cortisol may also be necessary.

The advent of computed tomography (CT) has provided a non-invasive and accurate means of visualising the normal ${ }^{5}$ and tumorous adrenal gland..$^{6-8}$ The technique is also valuable in identifying small lesions in the lungs, mediastinum, and pancreas, ${ }^{910}$ areas which are common sites of primary ectopic ACTH-secreting tumours. ${ }^{11}$ We therefore reviewed the use of CT in a large series of patients with Cushing's syndrome of various causes to define its value in the investigation of this condition.

\section{Patients and methods}

CT scans were performed on 37 patients with biochemically confirmed Cushing's syndrome from two endocrine units ( $\mathrm{St}$ Bartholomew's Hospital and the Royal Postgraduate Medical School). Thirty-five of these patients were untreated at the time of CT scanning; the other two had had adrenalectomies, one subtotal and the other bilateral.

Ten patients had adrenal adenomas found at surgery; all were successfully removed and the diagnosis confirmed by histological examination of the tumour and subsequent clinical cure. Five patients had adrenal carcinomas proved at surgery or necropsy, with macroscopic and histological evidence of malignancy.

Ten patients had pituitary-dependent Cushing's disease on the basis of plasma cortisol suppression after high-dose dexamethasone (DXM) (2 mg 6-hourly for 48 hours). Nine showed higher concentrations of ACTH in the jugular vein than in peripheral veins at venous sampling and a pituitary tumour was removed from the tenth.

Twelve patients were presumed to have ectopic ACTH-secreting tumours. All showed absence of plasma cortisol suppression on highdose DXM and had ACTH concentrations of $64-1471 \mathrm{ng} / 1.12$ In six patients ectopic sources were proved by surgical removal of the tumour and subsequent immunocytochemistry. In the remaining six 
the source was not identified despite extensive investigation, although three showed evidence of metastatic carcinoid disease with positive tissue immunostaining for ACTH.

\section{CT scanning}

Thirty-one patients were scanned at St Bartholomew's Hospital and six at the BUPA Medical Centre with an EMI 5005 body scanner. The adrenal area was examined at $1-\mathrm{cm}$ slice intervals (slice thickness $1.3 \mathrm{~cm}$ ) with intervening cuts when necessary. ${ }^{13}$ The normal thickness of either adrenal gland was taken as $1 \mathrm{~cm}$ or less. ${ }^{13}{ }^{14} \mathrm{In}$ the 12 patients in whom an ectopic source of ACTH was suspected scans of the chest and pancreas were also obtained.

All patients had oral gastrografin to opacify the stomach and small bowel, and antiperistaltic agents were given to reduce gut motility. Intravenous contrast was given in some patients, either to differentiate an adrenal mass from the adjacent kidney or to enhance vascular structures in the anterior mediastinum or upper abdomen. The average time taken to scan the adrenals was 20 minutes, and a complete scan of the chest and upper abdomen took about an hour.

\section{Results}

ADRENAL TUMOURS

CT correctly localised all 10 adrenal adenomas, seven on the right and three on the left (table I). All were rounded and well circumscribed; the maximum diameter on CT ranged from 2.5 to $6.5 \mathrm{~cm}$ (fig 1). structures, suggesting malignancy, and two patients also had metastases. The opposite adrenal gland was normal in contour but appeared small, never exceeding $0.7 \mathrm{~cm}$.

The use of CT early in the investigation of five severely ill patients (cases $2,9,11,13$, and 15) resulted in the detection of an adrenal tumour within 24 hours of their admission to hospital.

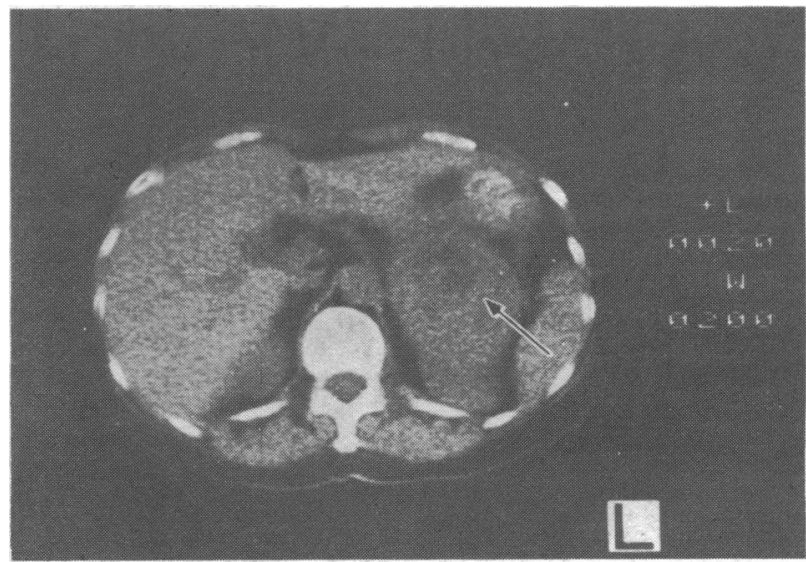

FIG 2-Left adrenal carcinoma infiltrating the liver $(8 \times 8 \mathrm{~cm})$.

TABLE I-Details of adrenal tumours

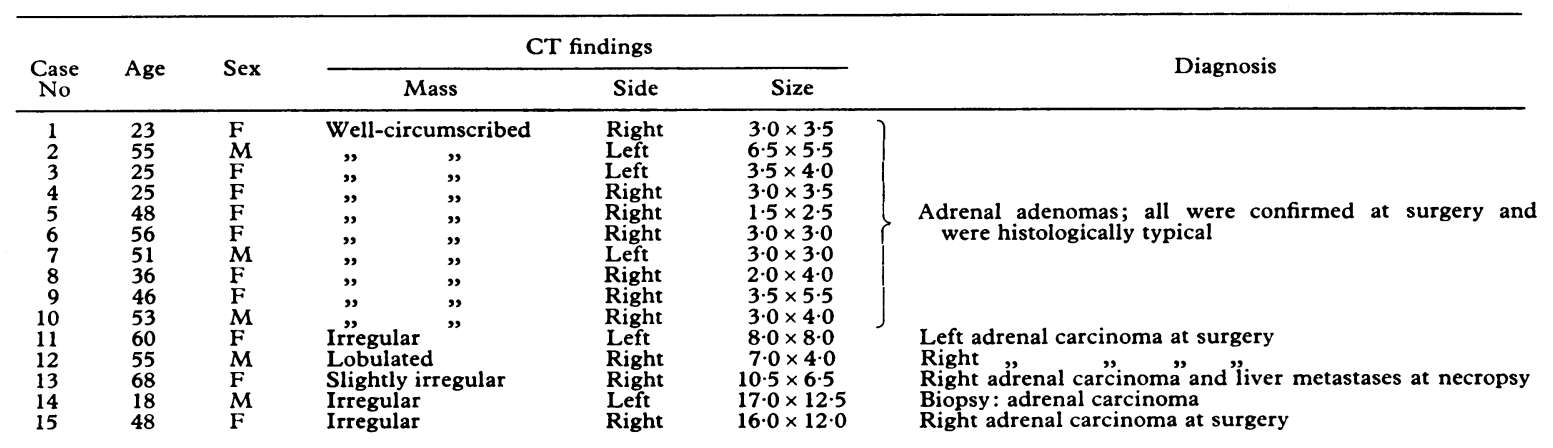

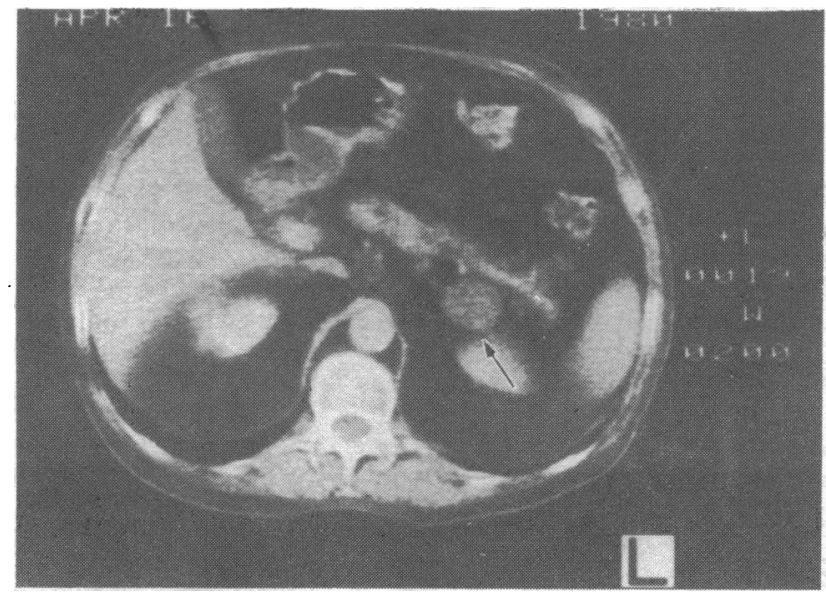

FIG 1-Left adrenal adenoma $(3.5 \times 3.5 \mathrm{~cm})$.

Contralateral glands were always normal in contour but tended to be smaller than usual, the maximum thickness never exceeding $0.7 \mathrm{~cm}$. All five carcinomas were correctly identified; all were irregular or lobulated in outline (fig 2). These ranged in size from 7 to $17 \mathrm{~cm}$ (maximum diameter). All showed signs of infiltration into adjacent

\section{ACTH-DEPENDENT CAUSES}

Of 10 patients with pituitary-dependent Cushing's syndrome, nine had adrenal glands within normal limits, and one with the longest history (over eight years) had bilateral nodules, subsequently shown by histological examination to be nodular hyperplasia.

Twelve patients had suspected ectopic ACTH-secreting tumours. Two had already been treated by adrenalectomy before CT studies. Of the 10 untreated patients, the adrenal glands were normal in size in three but obviously bilaterally enlarged in six (the thickness of the glands ranging from 1.4 to $2.8 \mathrm{~cm}$ ). One patient with a seven-year history had bilateral nodules, which were shown after adrenalectomy to be nodular hyperplasia.

All 12 patients had CT scans of the thorax and upper abdomen (table II), and an ectopic source was correctly localised in five. Three patients had small $(<1.5 \mathrm{~cm}$ ), solitary, peripheral nodules in the lung, two being visible as indistinct coin lesions on chest $x$-ray film, while the third (fig 3 ) could not be visualised by any other radiological means, including tomography of the abnormal area shown on the CT scan. In a further patient CT confirmed the presence of a pancreatic mass, previously visualised by both ultrasound and arteriography. In one other CT showed a mass in the anterior mediastinum which had not been shown on conventional tomography but which had been suspected from raised ACTH concentrations from the thymic vein sample taken at venous catheterisation.

In the remaining seven cases no primary ectopic tumour was detected with CT or any other radiological technique, including tomography, bronchoscopy, or selective venous sampling. In one 
patient a 1-cm ACTH-containing appendicular carcinoid tumour was subsequently removed at surgery, and the patient has since shown complete clinical remission. Three patients had evidence of metastatic carcinoid tumours at necropsy or surgery but in none was a primary tumour shown.

\section{Discussion}

In Cushing's syndrome due to an adrenal tumour the lateralisation and differentiation of a benign from a malignant tumour have previously required the use of time-consuming and often invasive investigations in patients who may be seriously ill. This study has shown that CT rapidly and accurately located all adrenal tumours and correctly differentiated the five carcinomas from the 10 benign adenomas.

Alternative techniques to determine the site of an adrenal tumour include radionuclide imaging, which has been widely used in Cushing's syndrome. ${ }^{3}$ It is, however, unreliable in the patients. It appears to be more accurate in determining the site of a tumour than the alternative techniques and is less invasive than any except ultrasound.

In evaluating an adrenal mass it is not possible to distinguish a primary from a secondary tumour with CT; but this is a limitation common to all radiological techniques. In this series all patients with proved primary adrenal tumours had an opposite gland which appeared smaller than usual, whereas the patients with ACTH-dependent Cushing's syndrome had either normal sized or hyperplastic adrenal glands.

Obvious bilateral adrenal enlargement was seen only in patients with an ectopic ACTH-producing tumour. This observation is in keeping with the pathological findings at adrenalectomy, where the adrenals from patients with an ectopic source of ACTH are much larger than those from patients with pituitary-dependent Cushing's syndrome. ${ }^{11} 18$ The detection of obvious bilateral enlargement on CT should therefore alert the clinician to the probable presence of an ectopic ACTHsecreting tumour.

TABLE II-Patients with ectopic source of ACTH

\begin{tabular}{|c|c|c|c|c|}
\hline $\begin{array}{l}\text { Case } \\
\text { No }\end{array}$ & Age & Sex & CT findings & Diagnosis at operation or necropsy \\
\hline $\begin{array}{l}16 \\
17 \\
18 \\
19 \\
20 \\
21 \\
22\end{array}$ & $\begin{array}{l}38 \\
26 \\
29 \\
35 \\
36 \\
33 \\
55\end{array}$ & $\begin{array}{l}F \\
F \\
M \\
M \\
F \\
M \\
F\end{array}$ & $\begin{array}{l}1.5 \mathrm{~cm} \text { solitary opacity left lung base } \\
1.0 \mathrm{~cm} \text { solitary opacity right lung base } \\
1.5 \mathrm{~cm} \text { solitary opacity right lung base } \\
\text { Lobulated mass in tail of pancreas } \\
3.5 \mathrm{~cm} \text { mass anterior mediastinum } \\
\text { Normal } \\
\text { Basal consolidation in lungs, no definite }\end{array}$ & \multirow{6}{*}{$\begin{array}{l}\text { Lung: carcinoid tumour } \\
\text { Lung: carcinoid tumour } \\
\text { Lung: carcinoid tumour } \\
\text { Pancreatic tumour } \\
\text { Thymic tumour } \\
1.0 \mathrm{~cm} \text { carcinoid tumour of appendix } \\
\text { Necropsy: } 0.5 \mathrm{~cm} \text { node containing carcinoid cells } \\
\text { in anterior mediastinum, no primary found } \\
\text { Necropsy: small secondary carcinoid deposits in } \\
\text { liver, no primary found } \\
\text { Microscopic metastatic carcinoid in adrenals and } \\
\text { liver at surgery, no primary found }\end{array}$} \\
\hline 23 & 69 & $\mathrm{~F}$ & $\begin{array}{l}\text { lesion } \\
\text { Mediastinum and pancreas normal }\end{array}$ & \\
\hline 24 & 75 & $\mathbf{F}$ & $\begin{array}{l}3 \text { areas of non-specific shadowing in } \\
\text { lungs; liver: secondary deposits }\end{array}$ & \\
\hline 25 & 49 & $\mathbf{M}$ & $\begin{array}{l}\text { Ill-defined opacity right lung above } \\
\text { hilum and areas of basal fibrosis }\end{array}$ & \\
\hline 26 & 69 & $\mathbf{M}$ & $\begin{array}{l}\text { Ill-defined opacity right lung level of } \\
\text { hilum }\end{array}$ & \\
\hline 27 & 64 & $\mathbf{M}$ & $\begin{array}{l}\text { Ill-defined opacity at right heart } \\
\text { border on } 3 \text { occasions }\end{array}$ & \\
\hline
\end{tabular}

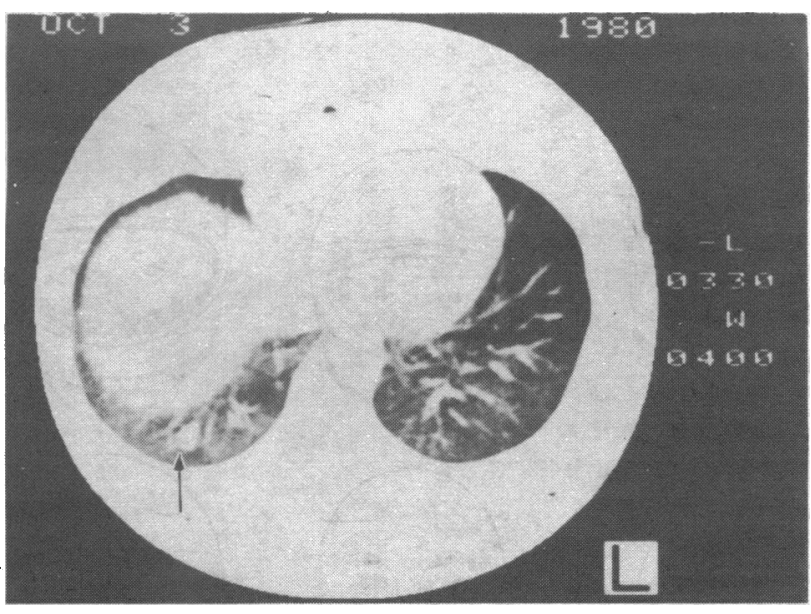

FIG 3-1-cm lung nodule deep in the right costophrenic recess (carcinoid tumour at surgery).

presence of an adrenal carcinoma, owing to the variable degree of uptake by such tumours, ${ }^{3}$ and is a time-consuming investigation, requiring several days before the scan can be interpreted, even with more recently introduced radionucleotides. ${ }^{15}$ Selective arteriography and venography have also been used to detect adrenal tumours but both are invasive and may be technically difficult. ${ }^{16}$ Ultrasound is non-invasive but normal adrenal glands are difficult to see, ${ }^{17}$ and small tumours may be missed.

CT of the adrenals is a rapid procedure requiring little co-operation from the patient-an important factor when dealing with very ill, uncooperative, or psychiatrically disturbed
Primary ectopic ACTH-secreting tumours most commonly occur in the lungs, anterior mediastinum, and pancreas. Locating these tumours by conventional techniques has often been unrewarding. In this series CT detected five out of 12 suspected ectopic tumours, in four of which it was the only investigation to show the lesion with sufficient confidence to allow surgical intervention. In those patients where CT failed to show an ectopic tumour all other techniques were similarly unsuccessful and in two patients no primary tumour site could be identified even at necropsy.

In conclusion, we have shown that $\mathrm{CT}$ provides valuable information in showing the adrenal anatomy in Cushing's syndrome simply and with immediacy. Its early use in the scheme of investigations should lead to an earlier definitive diagnosis and prompt instigation of appropriate treatment. In patients with the ectopic-ACTH syndrome CT is quicker, less invasive, and more successful than other radiological techniques in identifying and locating the tumour source of the ACTH.

We thank the trustees of St Bartholomew's Hospital for their generosity in purchasing the scanner and supporting FEW. Patients from the Hammersmith Hospital were under the care of Dr G F Joplin and we thank him for his advice on the manuscript. We also thank the staff of the BUPA Medical Centre for their co-operation and Mrs Julie Jessop for her secretarial help. MCW holds an MRC training fellowship.

Requests for reprints should be addressed to FEW.

\section{References}

${ }^{1}$ Scott HW, Liddle GW, Mulherin JL, McKenna TJ, Stroup SL, Rhamy RK. Surgical experience with Cushing's disease. Ann Surg 1977;185 524-33. 
2 Crapo L. Cushing's syndrome. A review of diagnostic tests. Metabolism $1979 ; 28: 955-77$.

${ }^{3}$ Britton KE. Radionuclide imaging in adrenal disease. In: James VHT, ed The adrenal gland. New York: Raven Press, 1979.

4 Corrigan DF, Schaaf M, Whaley RA, Czerwinski CL, Earll JM. Selective venous sampling to differentiate ectopic ACTH secretion from pituitary Cushing's syndrome. N Engl F Med 1977;296:861-2.

${ }^{5}$ Reynes CJ, Churchill R, Moncada R, Love L. Computed tomography of adrenal glands. Radiol Clin North Am 1979;17:91-104.

${ }^{6}$ Korobkin M, White EA, Kressel HY, Moss AA, Montagne J-P. Computed tomography in the diagnosis of adrenal disease. Am f Roentgenol 1979; 132:231-8.

7 Dunnick NR, Schaner EG, Doppman JL, Strott CA, Gill JR, Javadpour N. Computed tomography in adrenal tumours. Am $\mathcal{F}$ Roentgenol 1979 132:43-6.

${ }^{8}$ Eghrari M, McLoughlin MJ, Rosen IE, et al. The role of computed tomography in assessment of tumoral pathology of the adrenal glands. f Comput Assist Tomogr 1980;4:71-7.

${ }^{9}$ Muhm JR, Brown LR, Crowe JK, Sheedy PF Hattery RR Stephens DH Comparison of whole lung tomography and $\mathrm{CT}$ for detecting pulmonary nodules. Am 7 Roentgenol 1979;131:981-4.

${ }^{10}$ Sheedy PF II, Stephens DH, Hattery RR, MacCarty RL, Williamson B.
Computed tomography of the pancreas. Radiol Clin North Am 1977; $15: 349-66$.

11 Allott EN, Skelton MO. Increased adrenocortical activity associated with malignant disease. Lancet 1960 ;ii :278-84

12 Besser GM, Edwards CRW. Cushing's syndrome. In: Mason AS, ed. Clinics in endocrinology and metabolism. Vol 1(13). London: W B Saunders, 1972:451-90.

${ }^{13}$ Montagne J, Kressel HY, Korobkin M, Moss AA. Computed tomography of the normal adrenal glands. Am f Roentgenol 1978;130:963-6.

14 Karstaedt N, Sagel SS, Stanley RJ, Melson GL, Levitt RG. Computed tomography of the adrenal gland. Radiology 1978;129:723-30.

15 Ryo UY, Johnston AS, Kim I, Pinsky SM. Adrenal scanning and uptake with ${ }^{131}$ I-6/3-iodomethyl-nor-cholesterol. Radiology 1978;128:157-61.

${ }^{16}$ Sutton D. The radiological diagnosis of adrenal tumours. $\mathrm{Br} \mathcal{F}$ Radio $1975 ; 48: 237-58$.

17 Sample WF, Sarti DA. Computed tomography and gray scale ultrasonography of the adrenal gland: a comparative study. Radiology 1978 128:377-83.

18 Symington T. Functional pathology of the human adrenal gland. Edinburgh and London: E and S Livingstone Ltd, 1969:120.

(Accepted 30 November 1981)

\title{
Rebreathing in a subject wearing an integral crash helmet
}

\author{
R GREENBAUM, A F MALINS, R DAVIES, P J F BASKETT
}

\begin{abstract}
The respired air of a volunteer was analysed while he was wearing a variety of integral crash helmets. Observations were made with and without a protective balaclava, bib or scarf, or both. Rebreathing occurred and the peak inspired oxygen tension fell as low as $16.0 \mathrm{kPa}(120 \mathrm{~mm}$ $\mathrm{Hg}$ ) with a minimum inspired carbon dioxide of $2 \cdot 1 \mathrm{kPa}$ (16.0 mm Hg).

Accessories worn or attached to the helmet which restrict airflow into the helmet should not be used. Attention should be paid to the "air conditioning" of helmets when worn with flameproof balaclavas and bibs.
\end{abstract}

\section{Introduction}

The value of protective headgear in reducing the incidence of head injuries in motorcycle and autosport racing accidents has been established. ${ }^{1-3}$ The design of crash helmets was pioneered by neurosurgeons and other accident surgeons with head protection as the prime purpose. Schultz and Karlin in the USA have also argued the case for "full face" (integral) helmets. ${ }^{4}$

One of us (RD) observed that in a small number of motorcycle accidents a transient light-headedness or blackout may have preceded the accident and that in each of these cases, the victim was wearing an integral crash helmet with a scarf wrapped around his neck for protection against the cold. We therefore investigated the possibility that the wearing of integral crash helmets and accessories might lead to rebreathing.

Frenchay Hospital, Bristol BS16 1LE

R GREENBAUM, MB, FFARCS, consultant anaesthetist

A F MALINS, MB, FFARCS, senior registrar in anaesthetics

$R$ DAVIES, ambulanceman

P J F BASKETT, MB, FFARCS, consultant anaesthetist

\section{Methods}

The features of the helmets tested and accessories are illustrated in fig 1 . All the helmets were of integral design and some incorporated a vented visor or vents. The Stadium Achilles was unique in that it incorporated as an anti-misting device a "mouth cone" which resembled a full anaesthetic face mask (fig $1 a$ ). A motor racing driver may wear a flameproof balaclava and bib ( $e$ and $f$ ), and a motorcyclist
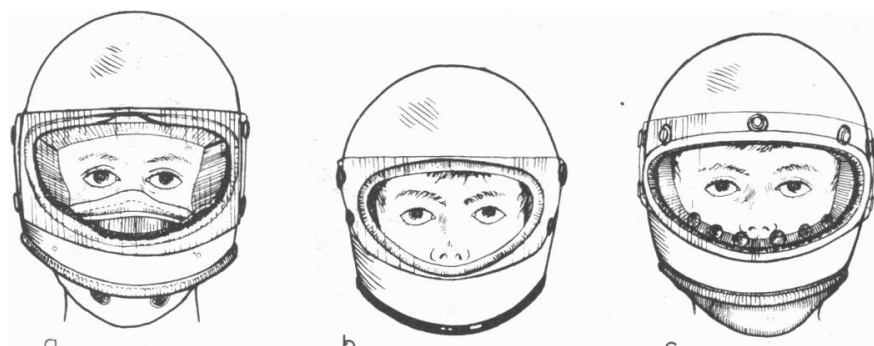

a

$b$
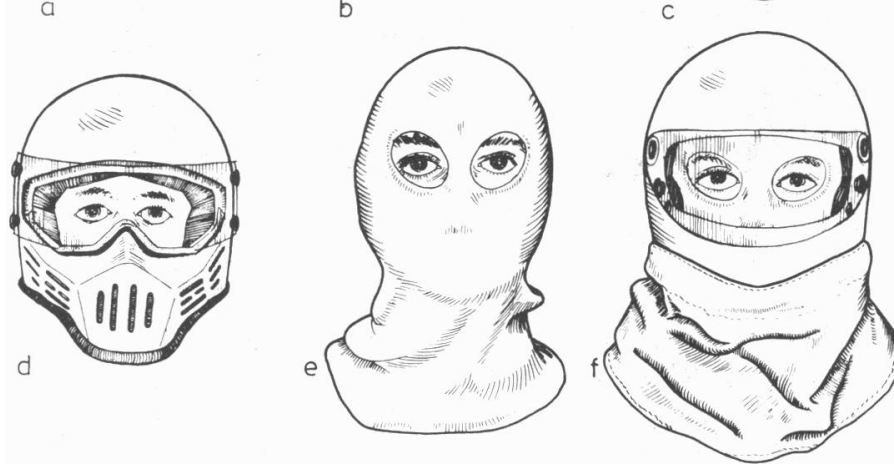

Helmets and accessories tested. (a) Achilles helmet made by Stadium Ltd Caerphilly, Glamorgan (complies with BS 2495 integral design, incorporates anti-mist mask). (b) Bell Star made by Bell Helmets Inc, California (complies with BS 2495, no vents). (c) Jetstar JHP made by Griffin Helmets, Halesowen (complies with BS 2495 , vented or non-vented visor). (d) RXM-1 made by Simpson Sports, Torrance, California (complies with Snell Foundation (USA) standard, flame filtration in nose piece). (e) Flameproof balaclava. $(f)$ Bell Star helmet with protective balaclava and bib. 